\title{
Immunosurveillance by gamma delta T cells - lessons from the cancer field
}

\author{
A C Hayday ${ }^{1,2^{*}}$, E Binda $^{1}$, A Robert $^{1}$, M Serrano ${ }^{1}$, F Dieli $^{3}$ \\ From 5th European Workshop on Immune-Mediated Inflammatory Diseases \\ Sitges-Barcelona, Spain. 1-3 December 2010
}

\section{Introduction}

The most common contemporary depiction of the immune response is an early innate response, mounted by myeloid cells, followed by a delayed adaptive lymphoid responses mounted by lymphocytes. This depiction is based on myriad compelling data sets and has made powerful predictions with biological and clinical relevance. Nonetheless, it seems incomplete. Thus, there are lymphocytes that respond very rapidly, commonly to self-encoded molecules over-expressed by dysregulated and/or transformed tissues and cells. The evidence for such "lymphoid stress-surveillance" by gamma delta $\mathrm{T}$ cells has been provided by animal models, and supports ongoing clinical investigations of the potential host-protective role of gamma delta $\mathrm{T}$ cells in cancer.

\section{Aim}

To determine whether aminobisphosphonate treatments with and without cytokines activate gamma delta $\mathrm{T}$ cells in patients, and to determine whether any such activation is safe and/or efficacious.

\section{Patients and methods}

The phenotype and functional potentials of gamma delta $\mathrm{T}$ cells have been monitored in a spectrum of patients receiving zoledronate (zometa), while the activation of gamma delta $\mathrm{T}$ cells in situ was attempted in a small two arm trial carcinoma patients, using zoledronate with and without interleukin-2.

\section{Results}

The most consistent response appears to be an upregulation of an activating receptor, NKG2D, which can mediate the functional response to transformed cells. In the small two arm trial in prostate and breast cancer, there were good indicators of safety and functional activation, including the consistent upregulation of cytolyitc mediators and interferon-gamma. However, cell exhaustion proved to be a concern. This provoked the idea of coupling gamma delta cell activation in vivo with adoptive cell transfer, studies of which are now ongoing, and will be presented.

\section{Conclusions}

The lymphoid stress-surveillance responsiveness of gamma delta $\mathrm{T}$ cells has many biological characteristics desired of cancer immunotherapy. Ongoing experiments in several countries collectively show good safety and promising results. Moreover, there is the potential for such treatment to strongly synergise with chemotherapy.

\section{Author details}

'Biomedical Research Centre, Guy's and St Thomas' Hospitals and King's College London, UK. ${ }^{2}$ London Research Institute, CRUK. ${ }^{3}$ University of Palermo, Italy.

\section{Published: 25 November 2010}

\section{Reference}

1. Dieli F, Vermijlen D, Fulfaro F, Caccamo N, Mariviglia S, Cicero G, Roberts A, Buccheri S, D'Asaro M, Gebbia N, Salerno A, Eberl M, Hayday A: "Targetting human gamma delta T cells with zoledronate and interleukin-2 for immunotherapy of hormone-refractory prostate cancer". Cancer Research 2007, 67:7450-7.

doi:10.1186/1479-5876-8-S1-I1

Cite this article as: Hayday et al:: Immunosurveillance by gamma delta T cells - lessons from the cancer field. Journal of Translational Medicine 2010 8(Suppl 1):11. 